\title{
Teoria Tríplice Hélice: $O$ que as pesquisas dos programas de pós-graduação
}

\section{brasileiros apresentam?}

\author{
Triple Helix Theory: What does the research of the Brazilian Postgraduate Programs present? \\ Teoría de la Triple Hélice: ¿Qué presenta la investigación de los Posgrados Brasileños?
}

Recebido: 08/07/2021 | Revisado: 10/07/2021 | Aceito: 11/07/2021 | Publicado: 27/07/2021

\author{
Ijean Gomes Riedo \\ ORCID: https://orcid.org/0000-0001-9159-8703 \\ Universidade Estadual do Oeste do Paraná, Brasil \\ E-mail: ijeanriedo@gmail.com \\ Aldi Feiden \\ ORCID: https://orcid.org/0000-0002-6823-9291 \\ Universidade Estadual do Oeste do Paraná, Brasil \\ E-mail: aldi.feiden@gmail.com
}

\section{Resumo}

O estudo realizou revisão sistemática das pesquisas em Programas de Pós-Graduação brasileiros sobre a teoria Tríplice Hélice. A base de dados utilizada foi o catálogo de dissertações e teses brasileiras, disponível na Plataforma Sucupira da CAPES. Admitiu-se todas as produções acadêmicas sobre Tríplice Hélice, referenciadas no catálogo brasileiro. Os principais resultados da pesquisa mostraram a existência de pouca relação institucional e formas estratégicas conjuntas nas tomadas de decisão brasileiras. O número de produções brasileiras sobre Tríplice Hélice é incipiente (169 trabalhos científicos), considerando o período 1995-2021. O maior volume de produção sobre o tema está nos Programas de PósGraduação em Administração e o estado com maior expressividade de pesquisas defendidas, foi Santa Catarina. Baseando-se na Tríplice Hélice, as principais necessidades diagnosticadas na pesquisa foram: Empregar esforços para constituir e sistematizar relações sinérgicas entre os agentes institucionais; Estruturar redes de interação para tomadas de decisões assertivas; Aplicar indicadores de desempenho sustentável ao desenvolvimento institucional; Favorecer laços comportamentais sólidos entre os agentes do conhecimento; Estruturar sistemas estratégicos para o desenvolvimento nacional.

Palavras-chave: Inovação; Instituições; Estratégias; Redes; Revisão sistemática.

\begin{abstract}
The study carried out a systematic review of research in Brazilian Postgraduate Programs on the Triple Helix theory. The database used was the catalog of Brazilian dissertations and theses, available on the CAPES Sucupira Platform. All academic productions on the Triple Helix, referenced in the Brazilian catalog, were admitted. The main results of the research showed the existence of little institutional relationship and joint strategic forms in Brazilian decision-making. The number of Brazilian productions on the Triple Helix is incipient (169 scientific works), considering the period 1995-2021. The largest volume of production on the subject is in the Postgraduate Programs in Administration and the state with the highest number of defended researches was Catherine Saint. Based on the Triple Helix, the main needs diagnosed in the research were: To make efforts to establish and systematize synergistic relationships between institutional agents; Structuring interaction networks for assertive decision making; Apply sustainable performance indicators to institutional development; Favor planned behavioral bonds between knowledge agents; Structuring strategic systems for national development.
\end{abstract}

Keywords: Innovation; Institutions; Strategies; Networks; Systematic review.

\begin{abstract}
Resumen
El estudio llevó a cabo una revisión sistemática de la investigación en los programas de posgrado brasileños sobre la teoría de la Triple Hélice. La base de datos utilizada fue el catálogo de disertaciones y tesis brasileñas, disponible en la Plataforma CAPES Sucupira. Se admitieron todas las producciones académicas de la Triple Hélice, referenciadas en el catálogo brasileño. Los principales resultados de la investigación mostraron la existencia de escasa relación institucional y formas estratégicas conjuntas en la toma de decisiones brasileña. El número de producciones brasileñas en la Triple Hélice es incipiente (169 trabajos científicos), considerando el período 1995-2021. El mayor volumen de producción sobre el tema se encuentra en los Programas de Posgrado en Administración y el estado con mayor número de investigaciones defendidas fue Catherine Saint. A partir de la Triple Hélice, las principales necesidades diagnosticadas en la investigación fueron: Realizar esfuerzos para establecer y sistematizar relaciones sinérgicas entre agentes institucionales; Estructuración de redes de interacción para la toma de decisiones asertiva; Aplicar indicadores de desempeño sostenible al desarrollo institucional; Favorecer los lazos de comportamiento planificados entre los agentes del conocimiento; Estructuración de sistemas estratégicos para el desarrollo nacional.
\end{abstract}

Palabras clave: Innovación; Instituciones; Estrategias; Redes; Revisión sistemática. 


\section{Introdução}

O Brasil é um país com grandes potencialidades, em extensão territorial na América do Sul com 8,5 milhões de km², com uma população de aproximadamente 210,15 milhões de habitantes e um PIB per capita, em 2018, de R\$33.593,82 (IBGE, 2020). Desta forma, em relação ao desenvolvimento nacional, admitiu-se um compromisso de sustentabilidade, junto com outros 193 países do mundo. Esse compromisso é conhecido como Agenda 2030. Entretanto, nos últimos anos o Brasil tem apoiado poucas instituições para promover o desenvolvimento sustentável, por meio de estratégias, sinergias e integração de esforços (Mineiro et al., 2018).

Mediante isso, justifica-se este estudo no argumento de que existem diversos tipos de organizações, por meio de interações institucionais (Arranjos Produtivos, Câmaras Setoriais, Sistema Nacional de Inovação, Triângulo de Sábato, Ecossistemas de Produção, Clusters, entre outros), que contribuem, ou podem contribuir em curto, médio e longo prazo, para o desenvolvimento inovativo e sustentável da sociedade. Entretanto, ainda se tem acordos institucionais que focalizam apenas o desenvolvimento econômico (Pinsky et al., 2015; Mineiro et al., 2018). Em síntese, é possível perceber que carece de estratégias e inovações brasileiras dirigidas ao conceito do "desenvolvimento sustentável” (Mineiro et al., 2018, p. 14).

Ainda, durante muitas décadas, houve evoluções constantes nos contextos tecnológicos, desenvolvimentistas e institucionais, com vistas ao princípio da participação regulada e equilibrada (Costa, 2020). Mas, nota-se que as realidades e comportamentos percebidos na sociedade passam por mudanças estruturais constantes.

Neste contexto, objetivou-se neste estudo identificar e discutir sistematicamente o que os pesquisadores examinam sobre a Tríplice Hélice (TH) nos Programas de Pós-Graduação brasileiros. Admitiu-se ainda, as sugestões de trabalhos futuros de Mineiro et al. (2018, p. 89) sobre a "elaboração de [...] estudos sistemáticos em bases de dados distintas para reforçar ou não as constatações" da Tríplice Hélice, e de Pinsky et al. (2015, p. 246), sobre inovação, "uma análise aprofundada da produção acadêmica brasileira possibilitará identificar as conexões acadêmicas, indicar lacunas de conhecimento e oportunidades de pesquisas setoriais sobre a temática". Neste estudo, considera-se a inovação como os meios de transformações e como objetivos multidimensionais para o alcance do desenvolvimento institucional na sociedade (Pinsky et al., 2015).

Assim, definiu-se a estrutura desta pesquisa em quatro partes, sendo: a introdução com os objetivos e a justificativa do estudo; o referencial teórico, buscando conceituar sucintamente a teoria Tríplice Hélice; a metodologia, que discorre sobre a instrumentalização de análise, por meio da revisão sistemática de dissertações e teses brasileiras; e os resultados e discussões que foi promovida uma análise sistêmica de proposições, contribuições e considerações referente às pesquisas em Programas de Pós-Graduação brasileiros. Ao final do estudo, apresenta-se conclusões breves e sucintas dos autores do emprego da teoria Tríplice Hélice no Brasil.

\section{Referencial teórico}

Em 1981, a teoria das instituições foi compreendida, por North, em três elementos, uma teoria de direitos de propriedade, uma teoria do Estado e uma teoria da ideologia: Os direitos de propriedade estabelece incentivos econômicos individuais e coletivos; o Estado entra em seu modelo na medida em que um lado especifica e resguarda a estrutura dos direitos de propriedade; a ideologia torna-se imprescindível para compreender de que modo as diversas percepções subjetivas afetam a reação dos indivíduos numa realidade objetiva em transformação (COSTA, 2020).

Neste contexto, a compreensão do termo institucionalismo parte da tripartite: Propriedade, Estado e Ideologia (Costa, 2020). O significado de instituições abordados neste estudo, partem da definição de um conjunto de hábitos, rotinas, práticas estabelecidas, regras ou leis que regulam as relações e interações entre os indivíduos e grupos. Neste sentido, há uma distinção entre instituição e organizações. As organizações são estruturas formais, criadas conscientemente e que tem um propósito explícito (Edquist \& Johnson, 1997). 
As relações institucionais são os objetivos da Tríplice Hélice (figura 1) e podem facilitar e flexibilizar ações estratégicas para o desenvolvimento institucional da inovação. Entre outros aspectos, a Tríplice Hélice permite a junção das instituições Universidade-Indústria-Governo, favorecendo articulações e tomadas de decisões colaborativas (Mineiro et al., 2018).

Figura 1: Representação da Tríplice Hélice.

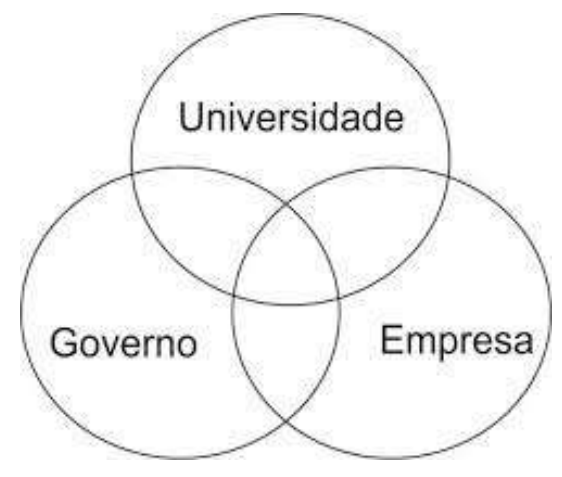

Fonte: Etzkowitz e Zhou (2017).

Segundo Etzkowitz e Zhou (2017) a Tríplice Hélice é considerada uma metodologia relacional e sinérgica, que permite examinar ambientes de trabalho e definir estratégias distributivas nas relações entre universidades, empresas e governos, com vistas ao desenvolvimento institucional.

\section{Metodologia}

A metodologia utilizada foi a revisão da literatura. O corte foi longitudinal, com busca de dados no Catálogo de Teses e Dissertações da CAPES. Diante do volume de dados obtidos, optou-se por realizar a revisão sistemática, pois permite uma compreensão aprofundada dos fatos e das temáticas abordadas (Tranfield, Denyer \& Smart, 2003).

O processo de revisão sistemática aplicado está ilustrado no fluxograma (figura 2), o qual descreve as etapas que constituem o processo de elaboração do estudo. A revisão da literatura é uma ferramenta-chave para tratar a interdisciplinaridade e a diversidade de conhecimento aplicado. Diante disso, a revisão da literatura - efetiva e não tendenciosa - precisa ser sistemática e se basear em processo estruturado e transparente, de modo a ser replicável, com isso, permitindo que as decisões e conclusões do revisor possam ser verificadas (Tranfield et al., 2003).

Neste estudo, replicou-se as metodologias utilizadas por Mineiro et al. (2018) e Valladares, Vasconcellos \& Di Serio (2014). Assim, após a leitura dos títulos, dos resumos e/ou das considerações finais das publicações referenciadas no catálogo, verificou-se que grande parte dos trabalhos não estavam relacionados à temática da pesquisa. Assim, foram excluídas 1.877 (91,74\%) pesquisas, por não estarem relacionadas ao conceito de Tríplice Hélice. Esse conceito parte da interação entre três atores principais - universidade, indústria e governo - para explicar as dinâmicas relacionais e sinérgicas (Mineiro et al., 2018). Por fim, após aplicação do critério de exclusão, restaram 169 pesquisas científicas (quadro 1). Estas foram classificadas, tagueadas e arquivadas.

Várias pesquisas (sete do Profissionalizante (Mestrado Profissional), 26 do Mestrado acadêmico e seis do Doutorado) estavam indisponíveis na Plataforma Sucupira do Ministério da Educação (MEC). Entretanto, buscou-se nas bibliotecas/repositórios das Universidades, para construção completa do arcabouço científico de pesquisas científicas sobre a Tríplice Hélice. 
Figura 1: Processos utilizados para elaborar a Revisão Sistemática.

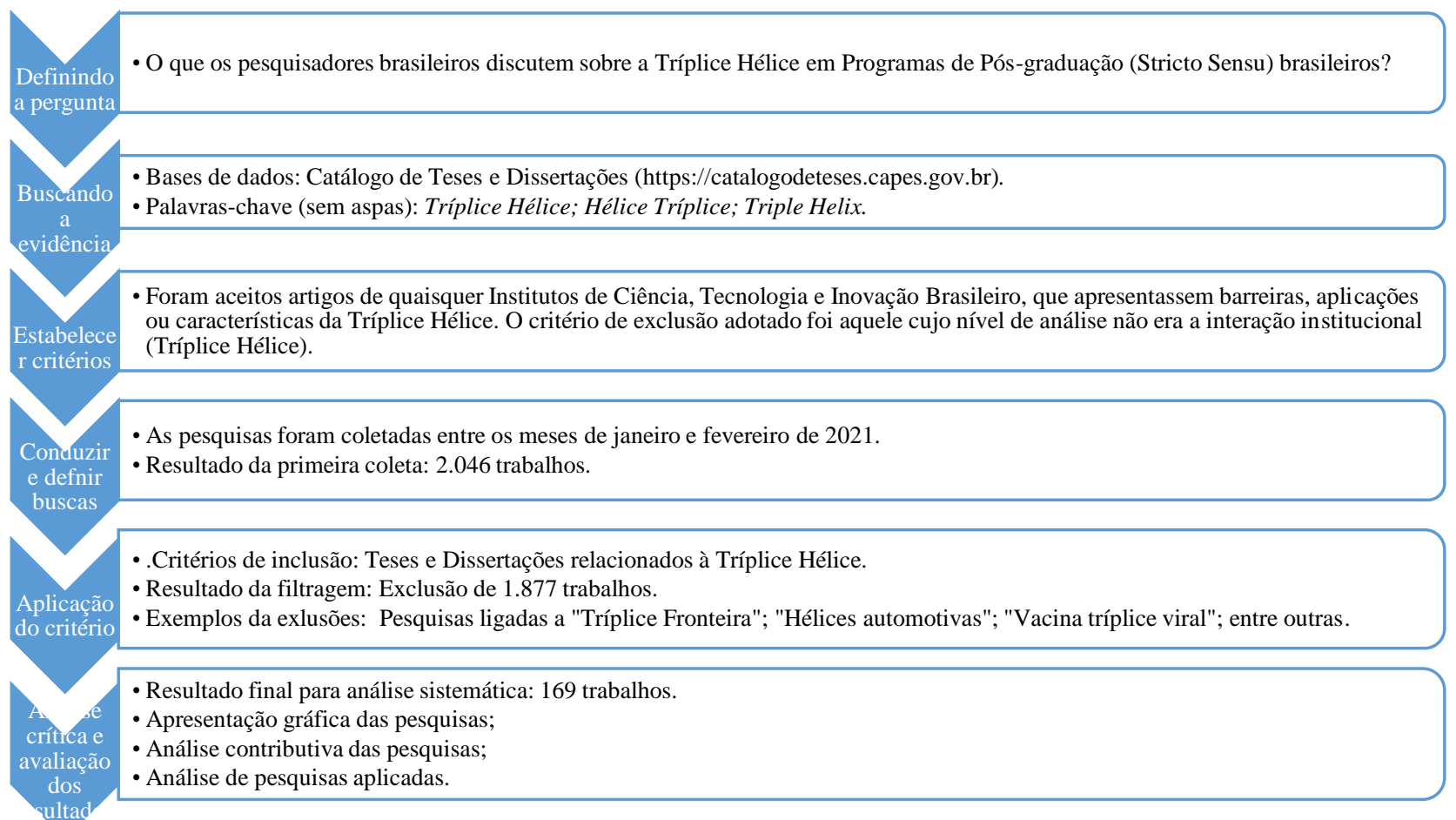

Fonte: Elaborado pelos autores, a partir de Tranfield et al. (2003).

Quadro 1: Número de Programas Pós-graduação pesquisados por nível de titulação

\begin{tabular}{|cc|}
\hline Titulação & Quantidade \\
Profissionalizante & 40 \\
Mestrado & 89 \\
Doutorado & 41 \\
\hline
\end{tabular}

Fonte: Autores.

Com base na leitura das pesquisas, três importantes discussões foram produzidas: a primeira foi caracterizar demograficamente (figuras) as pesquisas científicas sobre Tríplice Hélice. A segunda seção serviu para descrever quais bases teóricas foram cruzadas com o modelo analisado. E na terceira seção, objetivou-se analisar as pesquisas científicas aplicadas em dimensões da Teoria Institucional, servindo de base duas teses para compreender sobre os aspectos institucionais aplicados em estudos de caso consultados.

\section{Resultados}

A teoria Tríplice Hélice vem ganhando espaço no Brasil, entre os pesquisadores de instituições de ensino superior e os agentes envolvidos com o desenvolvimento da Ciência, Tecnologia e Inovação (figura 3). 
Research, Society and Development, v. 10, n. 9, e14410918036, 2021

(CC BY 4.0) | ISSN 2525-3409 | DOI: http://dx.doi.org/10.33448/rsd-v10i9.18036

Figura 2: Ranking das pesquisas sobre Tríplice Hélice por universidades brasileiras.

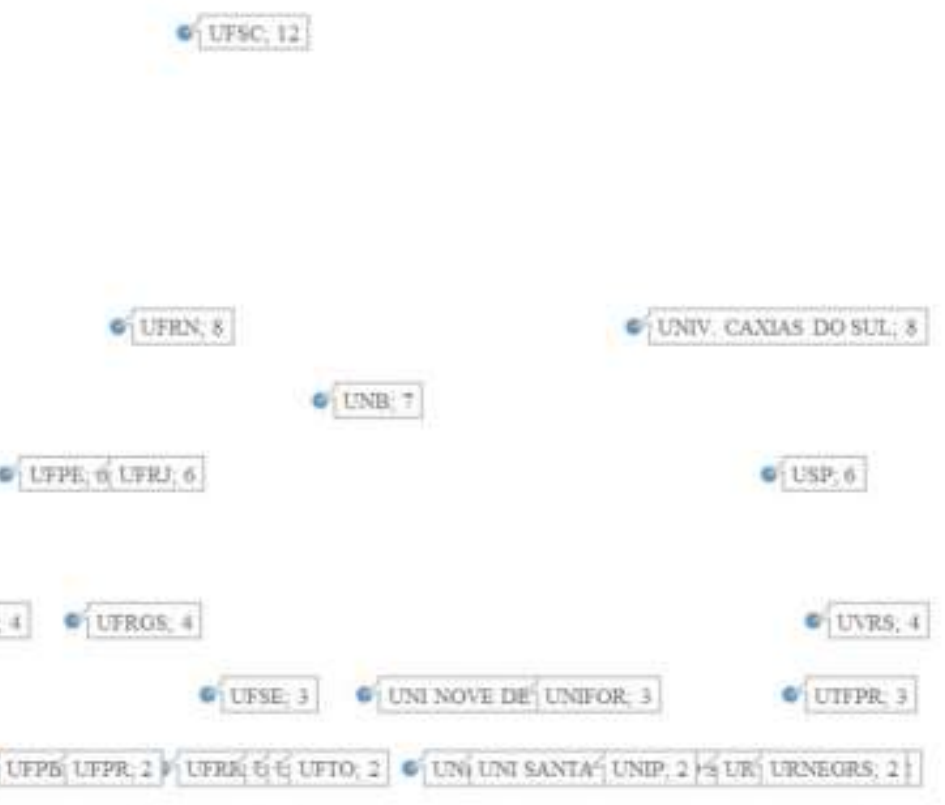

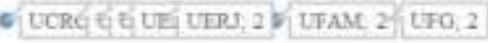

पFY

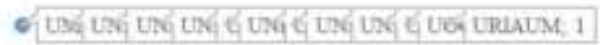

Legenda: O número de trabalhos defendidos está na frente das siglas das Universidades Brasileiras.

Fonte: Autores.

Neste contexto, Programas de Pós-graduação (Profissionalizante (Mestrado Profissional), Mestrado e Doutorado) brasileiros vêm debruçando esforços para pesquisas estratégicas e na formação de capital intelectual humano sinérgico. Os resultados mostraram que a partir de 2010 houve um crescimento significativo de trabalhos científicos sobre a teoria Tríplice Hélice (figura 4), para propiciar alternativas de interações institucionais ao desenvolvimento da sociedade nacional.

Figura 3: Quantidade versus datas de trabalhos defendidos sobre Tríplice Hélice nos Programas de Pós-Graduação brasileiros.

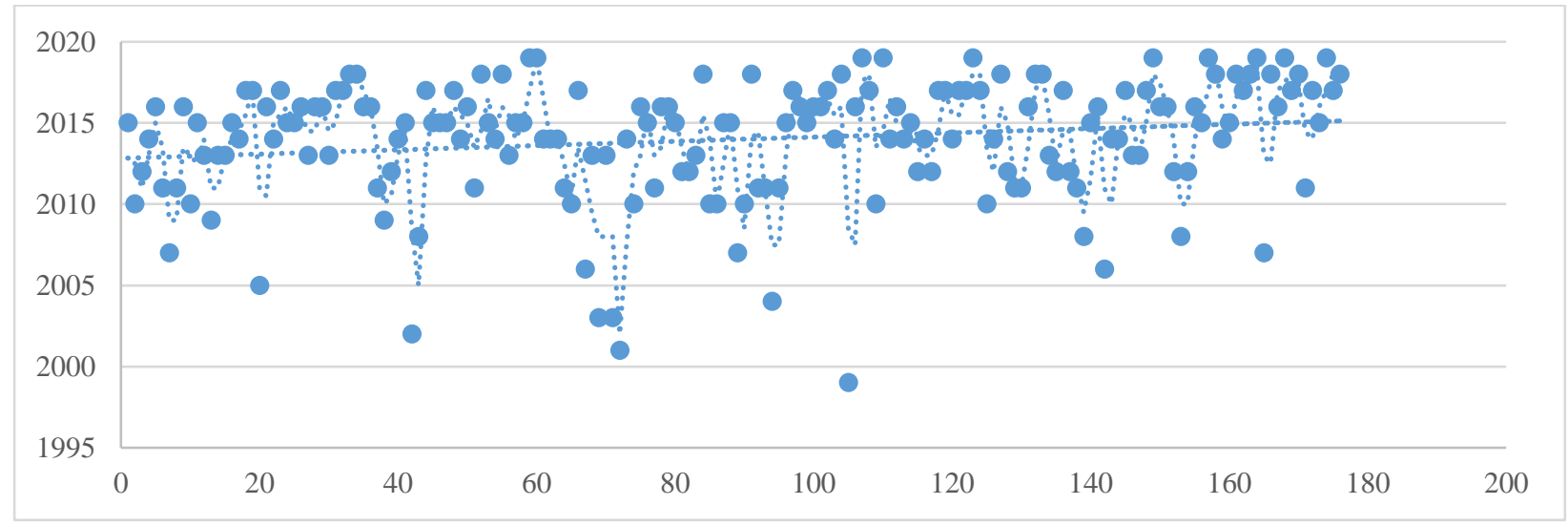

Legenda da coluna vertical: Ano de publicação; Coluna horizontal: Número de publicações.

Fonte: Autores.

Nota-se que o maior número de trabalhos defendidos sobre a Tríplice Hélice, foi no nível de titulação de mestrado (figura 5). No entanto, percebe-se que as pesquisas em nível de doutorado estão com aproximadamente no dobro de pesquisas do nível de mestrado. Entretanto, mesmo considerando o grau de significância dos números de pesquisas e a complexidade relacional das organizações, constata-se que a temática ainda como incipiente quanto a aplicação em estratégias de decisão e que o modelo precisa ser avaliado em contextos institucionais de diversas regionalidades. 
Figura 4: Ranking de trabalhos defendidos por titulação em Programas de Pós-Graduação brasileiros.

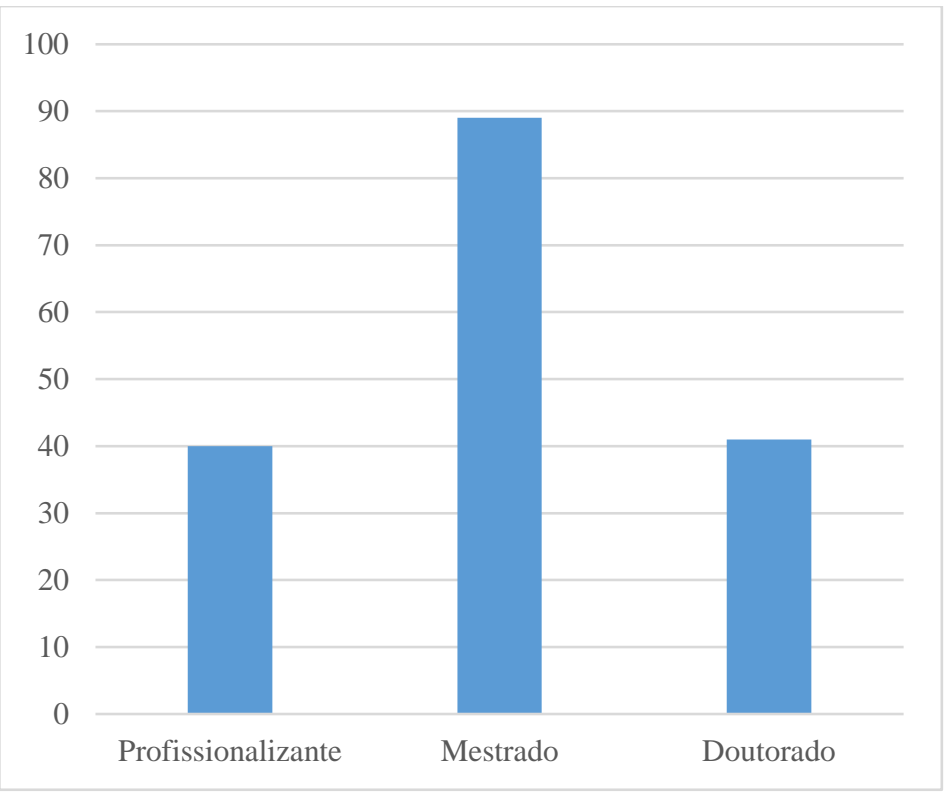

Fonte: Autores.

As pesquisas desenvolvidas abrangem várias áreas do conhecimento, permitindo diferentes compreensões e perspectivas, daquilo que se propõe a Tríplice Hélice (figura 6). Pode-se perceber na figura 6, que no nível de mestrado, o Programa de Pós-graduação que mais investiga sobre a temática é o de Administração, seguidos pelo de Desenvolvimento Regional e Engenharia de Produção. No entanto, percebe-se que a Tríplice Hélice está sendo examinada pelos brasileiros e pode ser relacionada a ciência interdisciplinar, pois é abordada em áreas do direito, economia, entre outros.

Figura 5: Ranking de trabalhos defendidos em nível de mestrado, por Programas de Pós-Graduação brasileiros.

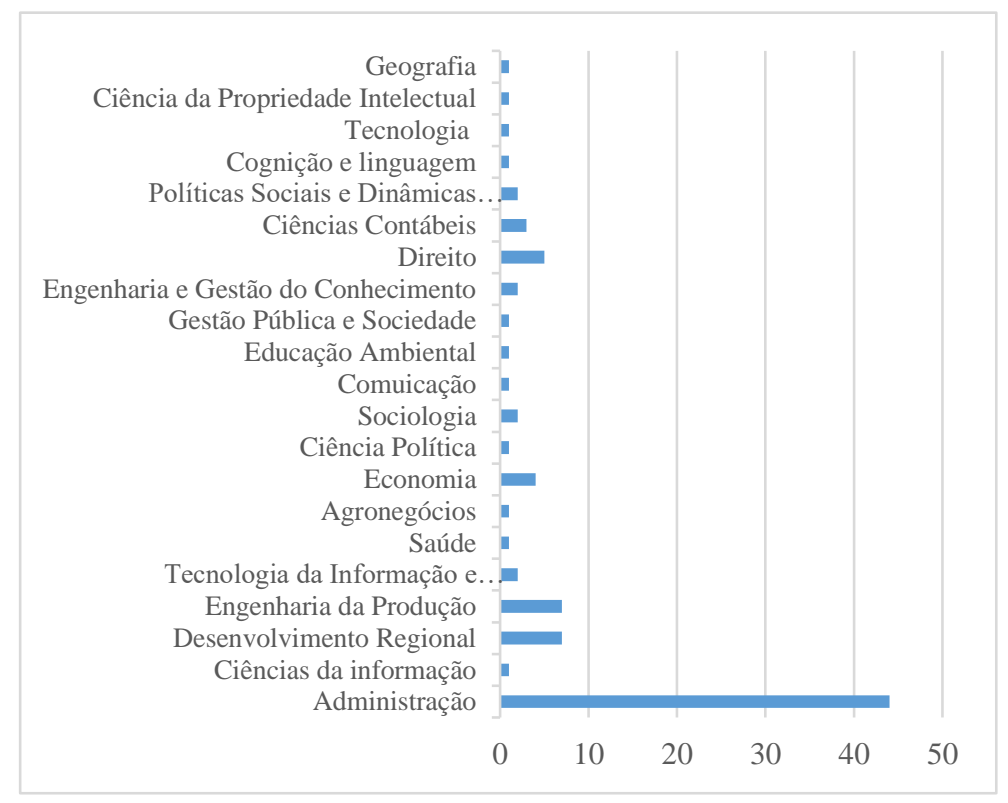

Fonte: Autores.

Na figura 7, observa-se que no nível de doutorado, os Programas de Pós-graduação com maior expressividade foi novamente o de Administração, seguido de Engenharia de Produção. No entanto, aparecem pesquisas sobre Tríplice Hélice em Programas de Pós-graduação interdisciplinares e que não haviam sido enfatizados no nível de mestrado. Isso faz questionar sobre as razões que os pesquisadores têm se predisposto a estudar a teoria Tríplice Hélice. 
Figura 6: Ranking de trabalhos defendidos em nível de doutorado, por Programas de Pós-Graduação brasileiros.

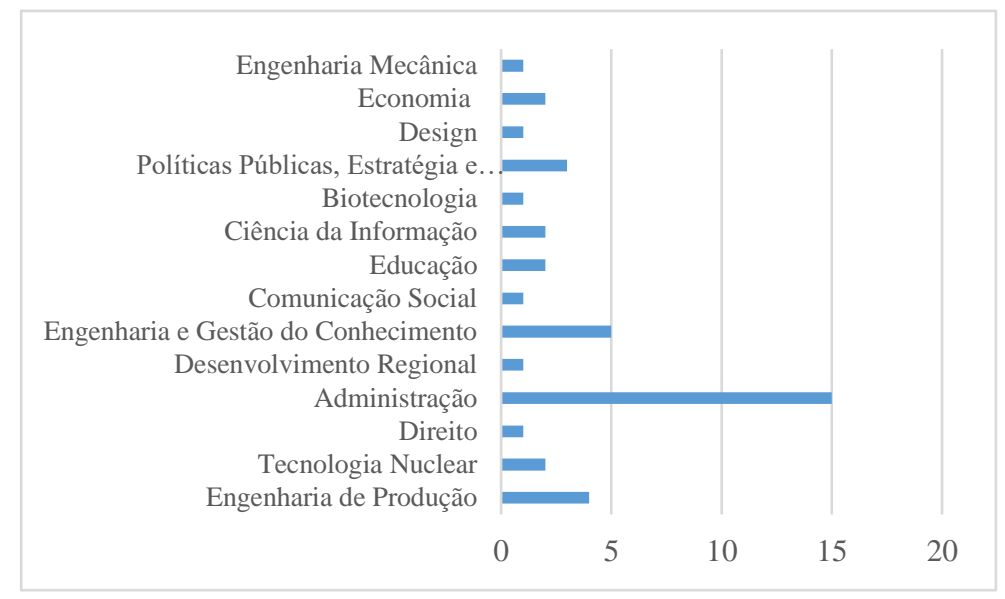

Fonte: Autores.

Já as dissertações dos cursos de Pós-graduação em nível Profissionalizante (Mestrado Profissional) estão configurados em primeiro o de administração. Nota-se aqui, que os Programas de Pós-graduação em Sistema de Gestão e Gestão de Políticas Públicas, ocupam espaços significativos nos interesses dos pesquisadores brasileiros. Ainda, percebe-se que os trabalhos científicos sobre a teoria Tríplice Hélice, ocupam espaços de discussão e aplicações em ambientes institucionais multifacetados (figura 8).

Figura 7: Ranking de trabalhos defendidos em nível Profissionalizante, por Programas de Pós-Graduação brasileiros.

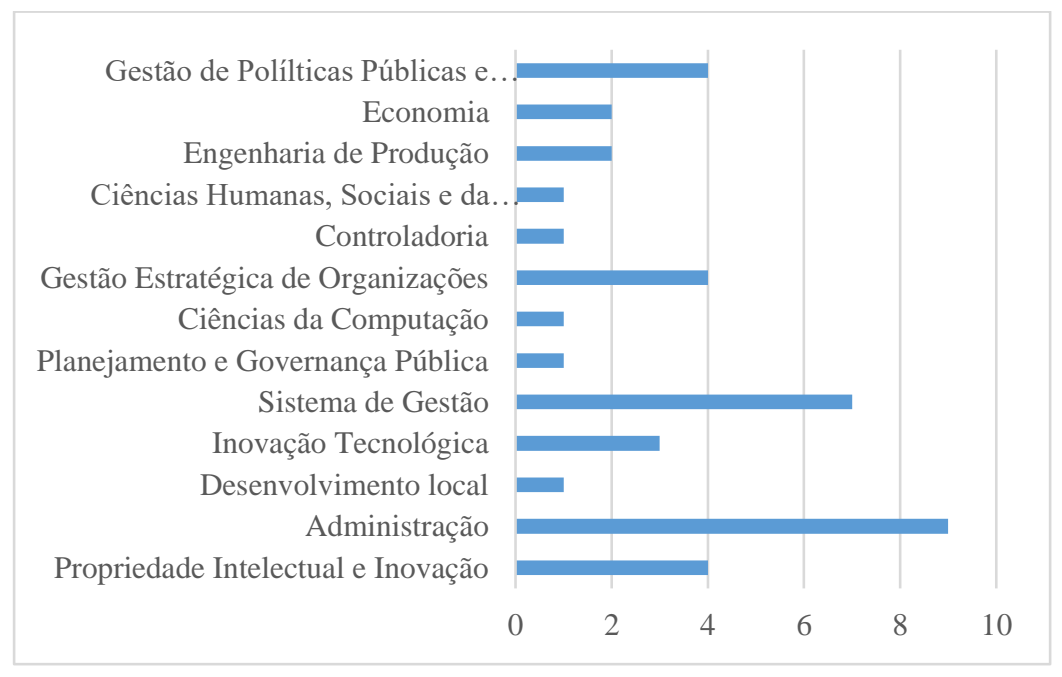

Fonte: Autores.

Então, compreende-se que as organizações universitárias se tornam importantes instrumentos para aliar a necessidade da sociedade e as promoções de desenvolvimento institucional. As fontes de dados solidificam as transferências de tecnologias baseadas nas gestões do conhecimento.

O alerta da importância de estudar a Tríplice Hélice, se dá ao fato da maioria das instituições desenvolverem atividades desconexas ou fragmentadas ao restante das instituições. O anseio de Etzkowitz \& Leydesdorff (1995), que se apoiou nas contribuições de Joseph Schumpeter (inovação) e Douglass North (Instituições), foi que as instituições contribuíssem em uma forma interativa para o desenvolvimento institucional. 
Por fim, o entendimento foi que as contribuições dos pesquisadores foram que as relações institucionais são fatores indissociáveis ao sucesso e ao desenvolvimento de tecnologias. As pesquisas dos eixos tecnológicos ou sociais permitem o alcance de cooperações institucionais, para mitigar os efeitos dos papeis conflituosos. Outro aspecto considerado, foi que a transferência de tecnologia relativiza a teoria com as práticas relacionais dos agentes institucionais, conforme pode ser examinado na próxima seção.

\section{Resultados}

\subsection{Contribuições das pesquisas científicas brasileiras}

A constituição de um sistema de inovação depende primordialmente de elementos culturais, locais e políticoadministrativos (fatores endógenos). Esses elementos são peculiares a cada região, bem como os níveis de interações e cooperações, existentes em ações desenvolvidas pelas instituições que administram a inovação no sistema. Portanto, evidenciase que a cultura empreendedora das empresas é empenhada por estratégias e vantagens competitivas (Sacramento, 2011; Kohl, 2012; Marinho, 2014; Ribeiro, 2017b).

Foi unanime pelos autores, que as mudanças institucionais na área da Ciência, Tecnologia e Inovação (CT\&I) vêm marcando décadas. A atual sociedade do conhecimento demanda instituições interagidas, especialmente em relação a universidades e políticas públicas, na qual emerjam perspectivas de desenvolvimento econômico, social e tecnológico (Brandão, 2012; Macedo, 2017; Moreira, 2019). Um exemplo é o caso do Porto Digital do Recife, que buscou por um ambiente estratégico e interinstitucional (por meio das relações Tríplice Hélice) para o desenvolvimento de projetos e iniciativas inovadoras, que estimulassem benefícios na sociedade e o desenvolvimento socioeconômico local (Silva, 2014a; Sousa, 2015a).

Costa (2013) e Silva (2015a) também buscaram identificar os processos de TH na inovação e no empreendedorismo em Fortaleza/CE. Figueiredo (2010), Silva (2010) e Lemos (2011) também observaram o processo de transferência de conhecimento da interação universidade-empresa. Os autores mencionados, concluíram suas pesquisas dissertando que os processos da TH ocorrem por meio de consultorias, ou seja, as interações e as sinergias necessitam ser contínuas.

Toscano (2014) e Kronbauer (2015) discorreram que a pesquisa conjunta é uma das formas para manter vantagens competitivas, pois as relações podem agregar valor no artefato ou conhecimento. Porém, os estudos identificaram que muitas empresas de Vitoria/ES e do estado do Rio Grande do Sul, respectivamente nos autores, não procuram universidades para a realização de soluções para seus negócios, por faltas de informações sobre as possibilidades de suas interações.

Por isso, as universidades necessitam estimular sinergicamente a inovação, através da construção de redes de relacionamento, por meio de Parques Científico e Tecnológicos (PCTs), personificando o papel da TH (Ribeiro, 2006; Nogueira, 2014; Barreiro, 2015). Exemplos disso, são os casos do Parque Zenit da UFRGS, do Parquelabs de Uberaba e do Parque Chapecó@, com suas implicações sociais, jurídicas e econômicas nas empresas incubadas ou associadas. O enfoque em redes relativiza o modelo $\mathrm{TH}$ aos efeitos heterogêneos das empresas privadas brasileiras, especialmente naquelas, cuja constituição é a geração da inovação para o mercado (Fontanela, 2016; Resende, 2016; Furlanetto, 2018; Paim, 2018).

Os principais objetivos, na visão de Mello (2017) e Ribeiro (2017b), dos PCTs são: fomentar a inovação; promover a cooperação institucional entre os atores envolvidos; as transferências tecnológicas contínuas; a consolidação de empresas inovadoras; e o desenvolvimento socioeconômico. Porém, no Brasil esse tema (TH) continua fragmentado, exigindo estudos mais sistêmicos, que incluam tanto os aspectos econômicos, quanto aos aspectos sociais e os ambientais para concepção de inovação e do empreendedorismo mais sustentáveis (Kasczuk, 2017; Schmitz, 2017).

Terra (1999) e Neves (2015) discorreram a importância das Fundações Públicas de Apoio e Fomento (FPAF) para amparar a pesquisa e a inovação dentro de universidades. Essa fundação permite o funcionamento da interação TH, tornando-se chave para o fomento do governo, na disponibilização de recursos ao desenvolvimento de estudos e projetos (Pontes, 2008). 
Exemplos disso, são os estudos de Bravin (2015), Ferreira (2018a) e Silva (2018a), que discorreram sobre a importância das FPAF para o desenvolvimento do PRONATEC Mulheres Mil, Programa Goiás Solar e Programa Conectando Saberes, respectivamente.

Aguiar (2015) e Brasileiro (2018) corroboraram com as afirmativas acima, que as relações TH propiciam o uso eficiente de recursos da FPAF brasileiras. Ainda, observaram que essas Fundações operam como ferramentas de desburocratização, tornando a gestão dos entes públicos mais ágeis, sobretudo para as ações nas instituições acadêmicas.

Assim, no uso de relações sinérgicas e o uso de redes de conhecimento e de relacionamento, a Tríplice Hélice passou a ser vista como importante fortaleza e oportunidade, tanto de sobrevivência de mercados, quanto de aquisição de vantagens competitivas para a economia brasileira (Santos, 2012; Camboim, 2013; Castillo, 2016; Brito, 2018).

Isso fica mais claro nas pesquisas de Silva (2012) no Ceará, Camboim (2013) no Rio Grande do Norte e Lyrio (2014) em Minas Gerais, quando avaliaram os impactos e os resultados da TH no desenvolvimento de projetos inovadores em micros e pequenas empresas. Os impactos mais relevantes dos três casos, foram os benefícios fiscais voltados para a inovação e o desenvolvimento de tecnologias, incluindo vantagens para a contratação de pesquisadores e aquisição de equipamentos e maquinários.

Então, este estudo assume que as universidades são importantes produtoras de conhecimento e utiliza todos os seus recursos para a elaboração de soluções emergentes; as empresas (organizações do setor produtivo; ou do setor industrial) são geradoras de tecnologias, fomentam ações e implementam na prática os protótipos desenvolvidos com/na universidade; e o governo (ou Estado) como formador de políticas públicas de apoio, regulação e fomento para o funcionamento da TH (Silva, 2015a; Riedo, 2017). Nota-se que esse sistema é aberto e propiciam vantagens competitivas aos segmentos produtivos, com desenvolvimento de novos produtos e/ou aprimoramento de produtos/serviços (Albuquerque, 2005; Siqueira, 2007).

Exemplo disso, são as estratégias de desenvolvimento institucional por meio de relações interativas de redes científicas e tecnológicas, como o caso entre a universidade Federal de Roraima (UFRR) e as empresas privadas de Roraima, onde apontam que as relações e o processo de cooperações TH existem e resolvem massivamente necessidades econômicas de empresas. Entretanto, observa-se que os impactos ambientais e sociais precisam ser observados, mas ainda são incipientes no processo desenvolvimentista (Silva, 2015b).

Obviamente, as universidades vêm sofrendo transformações contínuas, objetivadas em atender as obrigações precípuas de ensino, pesquisa e extensão, e mais recentemente assumindo um compromisso social e econômico, tornando-se universidades empreendedoras (Silva, 2014b; Morgades, 2016; Toledo, 2016). A inovação e o empreendedorismo no ambiente acadêmico, estão sendo estudados sob diversos rótulos, tais como: universidades inovadoras, universidade empreendedora, inovação acadêmica, empreendedorismo acadêmico, inovação universitária e empreendedorismo universitário (Rodrigues, 2016; Schmitz, 2017; Silva, 2018b; Blumm, 2019). Os termos levam consideração que o modelo TH, são alternativas de inovação para as empresas e fontes complementares de recursos à universidade (Bandeira, 2015).

Neste contexto, Almeida (2004), Toledo (2016) e Almeida (2017) buscaram informações das organizações universitárias brasileiras, especialmente sobre pesquisas e recursos humanos, e mais especificamente em programas de mestrados e doutorados. Nos estudos de Albuqerque (2012) fora especificado características de aumento de recursos financeiros para a Universidade Federal de Alagoas (UFAL), e de Eberhart (2013) para a Universidade Tecnológica Federal do Paraná (UTFPR). Como conclusões, os autores foram unanimes na afirmação de que aumentaram o número de publicações nos últimos anos, mas dissertaram que faltam estímulos para universidades e incubadoras, no que tange a facilitação de acesso aos recursos de apoio e fomento e desburocratização para criação de patentes.

Koste (2010), Carvalho (2011), Lain (2013) e Marinho (2014) examinaram os fatores da gestão da cooperação no sistema integrado da inovação do Brasil. Os autores mapearam os atores da inovação e seus papeis no Brasil (Koste, 2010; 
Carvalho, 2011; Marinho, 2014; Silva, 2019) e no Canadá (Armellini, 2013; Lain, 2013). Os resultados dos pesquisadores, foram que a cooperação e a inter-relação de instituições formam organizações hibridas, com respostas efetivas para os objetivos comuns dos mercados.

Já Silva (2015c) pesquisou sobre o emprego da TH aos processos adotados pelo Ministério da Defesa do Brasil e Brustolin (2014) comparou esses processos entre os países Brasil e Estados Unidos. Dalmarco (2012), por sua vez, analisou a horticultura nos países Holanda e Brasil. As conclusões dos autores, foram a incidência de recursos financeiros e intelectuais para a promoção da Ciência e Tecnologia nos países Estados Unidos e Holanda. Enquanto, na visão dos autores, o Brasil pouco forma ambientes de inovação social e tecnológica para o desenvolvimento institucional.

Assim, diversos pesquisadores analisaram os fatores de conhecimento que influenciam o desenvolvimento institucional, sob a luz da TH, despertado pelo interesse da sociedade. Consequentemente, os fatores influenciais explicitados pelos autores, foram: as redes; as consultorias e a gestão da cooperação; o fomento e a desburocratização; estratégias para a garantia da vantagem competitiva e para a dinamização da inovação; as organizações híbridas; os recursos intelectuais como fator primordial (Junior, 2008; Pires, 2008; Tosta, 2012; Avila, 2016; Machado, 2016; Riedo, 2017).

Enfim, a TH continua sendo reconhecida como uma abordagem que propõem o modelo de desenvolvimento institucional, que incentiva a criação de ambientes estratégicos constituídos por atores com valores locais e a transição baseada em sinergias de uma sociedade baseada no conhecimento (Quadros, 2011; Pavinato, 2018).

\subsection{Tríplice Hélice e suas relações}

O conhecimento na TH pode promover a transferência de tecnologia ao mercado. Essa transferência pode ser considerada, a partir de uma abordagem Schumpeteriana, um processo que tem seu início na revelação da inovação e no registro da patente, o que permite um avanço para a sustentabilidade econômica (Chais, 2014; 2017; Bittencourt, 2017).

Torres (2011) e Schreiner (2017) buscaram compreender a perspectiva da TH, como um grupo envolvido em um centro, que estabelece estratégias e decisões organizacionais para seu desenvolvimento. Dentre a extensa literatura sobre liderança, Zimba (2010) e Schreiner (2017) concluíram, sob a perspectiva construcionista, estudar a TH propicia formas colaborativas de trabalho em ambientes de inovação.

Com o propósito de ampliar o horizonte da análise da teoria TH, para além dos pressupostos teóricos, Forster (2016) e Silva (2017) discorreram que há necessidade de governança, permitindo direcionar esforços mercadológicos e relações estratégicas. Em relação a TH e a análise sociológica, Doin (2016), utilizou da análise de Ansell e Gash, para caracterizar essa governança como proposta colaborativa.

O papel das instituições torna-se imprescindível para o sistema econômico e para processo de desenvolvimento da inovação e da industrialização (Junior, 2008; Nascimento, 2010; Rodrigues, 2015; Andrade, 2016; Lira, 2017).

Neto (2015), sob a luz da teoria do crescimento de Robert Solow, descreveu a composição de uma economia como um pilar importante para a sociedade. Pois, o contexto brasileiro aponta para a existência de características sociopolíticas, que inibem a interconexão entre os partícipes desse processo no desenvolvimentista institucional (Rocha, 2014a; Neto, 2015; Andrade, 2016).

Outro exemplo são as análises institucionais que consideram as inovações sociais e tecnológicas, em conjunto, como motores do desenvolvimento institucional (Neto, 2016). A interação interinstitucional detém um papel fundamental para a geração e a difusão do conhecimento e para transformá-lo em produtos comercializáveis (Fiorin, 2016; Oliveira, 2019).

Renz (2016) resgatou as definições da Teoria do desenvolvimento endógeno, proposto por Barquero, e os resultados evidenciaram fatos no município de Santa Rosa, no Rio Grande do Sul, com impactos positivos alcançados nas relações ontológicas e no crivo de decisões situacionais. Já no estudo de Silva (2017), o pesquisador propôs analisar a influência do capital 
social na formação de estratégias de inovação no âmbito da gestão de PCT. Os ambientes de inovação mostram-se espaços de transferências de conhecimento que propiciam transformações de ideias em inovações mercadológicas (Junior, 2014; Anderle, 2017; Sartori, 2017; Bassani, 2018).

Lopes (2016) e Ferreira (2018b) dissertaram sobre a importância dos aspectos endógenos determinantes ao processo de desenvolvimento da inovação regional. Contudo, pesquisadores em PCTs, estão avaliando novas visões de interação, a qual incluem outras dimensões (hélices) ao modelo TH, na tentativa de propiciar vantagens competitivas e a flexibilização na troca de experiências (Sousa, 2019).

Pensando nisso, a teoria TH, recebeu novas hélices denominadas hélice quadrupla (sociedade civil) e quíntupla (meio ambiente/desenvolvimento sustentável). A ideia das hélices são para dinamizar o processo tecnológico trazendo novos expertises e propor ambiências mais amplas e democráticas (Santos, 2016; Webber, 2018; Mineiro, 2019; Sousa, 2019).

Neste contexto, a Tríplice Hélice pode ser considerada um rearranjo institucional, onde propicia a transformação do conhecimento em desenvolvimento, por meio de atividades fundadas em CT\&I (Neves, 2006; Niwa, 2014; Ferreira, 2015). Lembra-se que na $\mathrm{TH}$, as partes têm objetivos comuns e poderes equitativos.

Em detrimento as pesquisas realizadas, Bencke (2016) enfatizou, em seu estudo, as críticas de pesquisadores sobre a TH, explicitando que o modelo é utópico, genérico, descritivo e insuficiente em razão da complexidade de contextos específicos.

Mas, este estudo defende que para o desenvolvimento institucional acontecer, depende de várias estratégias de trabalho. Isso porque para os agentes cooperarem, deve haver sinergias, ou seja, depende de resultados para aumentar a capacidade de receitas e de investimentos (Rocha, 2002; Riedo, 2017; Webber, 2018). Exemplo disso é a busca do desenvolvimento regional, onde os agentes institucionais públicos, procuram alternativas para dinamizar suas economias e propiciem gerações benéficas de fatores sociais para a sociedade (Deboni, 2010; Correia, 2014; Silva, 2015a; Bulegon, 2019).

Por fim desta seção, entre os benefícios ou os malefícios dos sistemas de desenvolvimento institucional, é importante formar uma arquitetura jurídico-institucional de um ambiente inovativo (Aigner, 2011; Mello, 2015; Lima, 2019). Neste contexto, Shmitz (2017) apresentou um framework contratual sistêmico de inovação e de empreendedorismo para universidades, para fins de promover o desenvolvimento socioeconômico regional e a sustentabilidade institucional.

\subsection{Estudos de perspectivas aplicadas}

A Tríplice Hélice (TH) instrumentaliza um sistema de rede de relacionamento para a CT\&I. Sua interação com os segmentos produtivos foi auxiliada nas necessidades da sociedade e no papel fundamental da universidade, como indutora do processo extensionista de cada região (Christo, 2011; Pereira, 2013; Hoffmann, 2015).

Nesta perspectiva, a análise endógena de uma região propicia mecanismos estruturais de caracterização à inovação entre os atores, a partir do modelo teórico TH. No caso da Serra Gaúcha, no Rio Grande do Sul, Marchi (2014) e Bencke (2016) expressaram participação assídua dos agentes da TH, na busca de interações com agente externos, para captar recursos, buscar conhecimentos e aplicar no mercado.

Assim, analisar a efetividades da aplicação dos recursos públicos é primordial ao desenvolvimento de um país (Passoni, 2011; Anderle, 2017; Jaroszewski, 2018; Silva, 2018c). Os investimentos públicos no desenvolvimento da inovação, requer preparação/organização das universidades públicas, para acessar os editais de fomento públicos (Morone, 2003; Mesel, 2013; Silva, 2014c; Pereira, 2017). Neste contexto, enfatiza-se novamente as necessidades de Fundações de Apoio a captação de fomento para a alavancagem de inovação em seus graus de maturidade (Guedes, 2010; Nunes, 2013; Silva, 2016).

Lembra-se que na década de 90, a sociedade não esperava esse crescimento exponencial da inovação. Exemplo disso é o desenvolvimento da microeletrônica e das tecnologias de comunicação que foram emergidas sobre os paradigmas da tecnologia da informação, que transformada em conhecimento e inovação, desempenha um papel crucial para o desenvolvimento econômico 
(Mesquita, 2016; Sobrinho, 2017; Araujo, 2018). Por isso, Sobrinho (2017) e Piccini (2018) afirmaram que é necessária a construção de sistemas de inovação apropriados ao crescimento das inovações, com estruturas de depósitos desburocratizadas para patentes de inovações.

Em paralelo a essa discussão, este estudo realizou a análise sistemática (quadro 2) dos artigos coletados em seguimentos produtivos ou industriais, com as proposições de Costa (2017) e Ribeiro (2017a):

- Costa (2017) propôs um modelo de gestão estratégica e o modelo Balanced Scorecard (BSC) à TH. O autor constatou que os assuntos considerados mais relevantes sobre os arranjos da TH são: a cooperação, a gestão da propriedade intelectual, os mecanismos de gestão utilizados, os conflitos de interesses e o papel das instituições articuladoras da inovação.

- Ribeiro (2017a) propôs um modelo analítico baseado no modelo Balanced Scorecard, introduzindo a teoria da Gestão do Conhecimento à TH. O autor constatou que as dimensões para a cooperação TH são: estrutural, relacional, cognitiva e o contexto.

Quadro 2: Análise das perspectivas baseadas nas óticas de Costa (2017) e Ribeiro (2017a).

\begin{tabular}{|c|c|c|c|c|}
\hline \multirow[b]{2}{*}{ Áreas } & \multirow[b]{2}{*}{ Pesquisadores } & \multirow[b]{2}{*}{ Região da pesquisa } & \multicolumn{2}{|c|}{ Análises sistemáticas } \\
\hline & & & Costa (2017) & $\begin{array}{l}\text { Ribeiro } \\
\text { (2017a) }\end{array}$ \\
\hline Energia solar fotovoltaica & Castelo (2016) & Ceará & $\mathrm{C}$ & D \\
\hline Piscicultura & Riedo (2017) & Mato Grosso do Sul & $\mathrm{E}$ & $\mathrm{B}$ \\
\hline Soja & Sonego (2015) & Rio Grande do Sul & $\mathrm{A}$ & $\mathrm{C}$ \\
\hline Biodiesel & Soares (2009) & Nacional & $\mathrm{E}$ & $\mathrm{B}$ \\
\hline Carcinicultura & Filho (2009) & Rio Grande do Sul & $\mathrm{D}$ & A \\
\hline Vitivinicultura & Santos (2017) & Jundiaí/SP & A & A \\
\hline $\begin{array}{l}\text { Máquinas e implementos } \\
\text { agrícolas }\end{array}$ & Azevedo (2014) & Rio Grande do Sul & $\mathrm{C}$ & $\mathrm{D}$ \\
\hline Energia elétrica & $\begin{array}{c}\text { Dantas (2015); Guedes } \\
\text { (2010) }\end{array}$ & Nacional & $\mathrm{D}$ & A \\
\hline Audiovisual & Cardoso (2013) & Rio Grande do Sul & $\mathrm{C}$ & $\mathrm{C}$ \\
\hline Gás e Petróleo & $\begin{array}{l}\text { Rezende (2001); } \\
\text { Rezende (2012) }\end{array}$ & Rio Grande do Norte & $\mathrm{E}$ & $\mathrm{D}$ \\
\hline Construção civil & Cornélio (2011) & Paraná & $\mathrm{C}$ & $\mathrm{D}$ \\
\hline $\begin{array}{c}\text { Cooperativas de materiais } \\
\text { recicláveis }\end{array}$ & Ribeiro (2016) & Goiás & A & $\mathrm{C}$ \\
\hline Saúde suplementar & Feio (2011) & Nacional & $\mathrm{B}$ & A \\
\hline Café & Costa (2017) & Estado de São Paulo & A & $\mathrm{B}$ \\
\hline Biomateriais & Rocha (2014b) & Estado do Paraná & $\mathrm{B}$ & $\mathrm{C}$ \\
\hline Ovinocultura & Gomes (2014) & Mato Grosso do Sul & $\mathrm{D}$ & $\mathrm{D}$ \\
\hline Fármacos e Biociências & $\begin{array}{l}\text { Lacerda (2015a); Rocha } \\
\text { (2011) }\end{array}$ & Pernambuco e Rio de Janeiro & $\mathrm{E}$ & B \\
\hline Petróleo & $\begin{array}{l}\text { Calderan (2012); } \\
\text { Santos (2013) }\end{array}$ & Nacional & $\mathrm{B}$ & $\mathrm{B}$ \\
\hline Microcrédito & Silva (2007) & Ceará & $\mathrm{E}$ & A \\
\hline
\end{tabular}

Legenda para coluna Costa (2017): (A) Cooperação; (B) Gestão da propriedade intelectual; (C) Mecanismos de gestão utilizados; (D) Conflitos de interesses; (E) Papel das instituições articuladoras. Legenda para coluna Ribeiro (2017a): (A) Estrutural; (B) Relacional; (C) Cognitiva; (D) Contexto. Fonte: Autores.

Entende-se que a característica do processo da relações sinérgicas institucionais é um método sistêmico para a construção de tecnologias físicas e as tecnologias sociais (Filho, 2009; Neto, 2016; Coutinho, 2017). Evidencia-se o fato que nas universidades, os temas relacionados ao empreendedorismo social e a inovação social têm despertado, nas últimas décadas, a atenção de pesquisadores na área das ciências sociais e engenharias do Brasil e do mundo (João, 2014; Pradella, 2015; Mafioletti, 2016; Schneider, 2017).

Enquanto isso, nas empresas (organizações do setor produtivo; do setor industrial) têm-se a necessidade de praticar a Responsabilidade Social Corporativa, ou seja, papéis coadunas ao desenvolvimento sustentável, através da relação justa no 
mercado e preocupação com os fatores ambientais (Prates, 2013; Rodrigues, 2013; Cunha, 2015; Barroncas, 2017; Aloise, 2017). A educação ambiental é uma tratativa que deve ser discutida no âmbito da TH, com políticas públicas concatenadas a realidade nacional (Negalho, 2011; Santanna, 2014).

Por sua vez, as inovações sociais buscam alternativas e soluções para resolução de questões sociais (Santos, 2015). Uma característica relevante do processo de inovação social é a colaboração entre os múltiplos atores, por intermédio da formação de parcerias intersetoriais, que contempla em sua definição, o Estado, o setor empresarial, o terceiro setor, os indivíduos e comunidades. Neste sentido, as pesquisas e o desenvolvimento de produtos e serviços sociais, permitindo instrumentalizar a criação de tecnologias assistivas (Mafioletti, 2016).

Os frutos das incubadoras sociais são as tecnologias sociais (tecnologias de simplórias e de baixo custo). Estas são caracterizados como uma sugestão socioinovadora de desenvolvimento, que pode aliar o saber popular e a inclusão (Maleane, 2012; Santos, 2015; Ribeiro, 2016). A organização socioprodutiva e o conhecimento técnico-científico, considerando sua efetividade, configura a possibilidade de replicação e que vise o desenvolvimento sustentável (Borges, 2017; Jesus, 2018).

Por fim, o papel das instituições como ativos da sociedade, devem ser como geradores de aspectos socioeconômicos e o compromisso com o meio ambiente, torna-se sustentável (Cornelio, 2011; Ferreira, 2012; Azevedo, 2014; Cunha, 2015). Em suma, a teoria Tríplice Hélice necessita aplicar cada vez mais indicadores de sustentabilidade em suas práticas (Silva, 2011; Lacerda, 2015b; Mesquita, 2016).

\section{Conclusão}

No estudo é percebido que as pesquisas sobre Tríplice Hélice, nos Programas de Pós-Graduação brasileiros, iniciaram em 1999 e tiveram ápice em 2014. Admite-se que o papel das instituições ainda é muito fragmentado, mas essencial para a promoção de objetivos comuns. Assim, é necessário apoiar relações interinstitucionais consolidadas e sinérgicas, mas com respeito aos seus limites e o desenvolvimento sustentável.

A contemporaneidade permite visões interdisciplinares do desenvolvimento. Assim, no estudo, foi percebido que com o passar do tempo, foram agregadas novas hélices ao conceito Tríplice Hélice (meio ambiente e a sociedade). Entretanto, a visão democrática das relações e a identidade local/regional/cultural são os motores do desenvolvimento institucional sustentável.

As Instituições na região sul do Brasil foram as responsáveis pela maioria das pesquisas, sobretudo nos Programas de Pós-graduação em Administração. Foram unânimes as afirmações que as universidades são a dimensão primordial para o desenvolvimento das inovações tecnológicas e sociais brasileiras.

As aplicações das relações interinstitucionais permitem aplicação de medidas de intervenção ou de facilitação para o comportamento planejado dos agentes. Os recursos intelectuais são aspectos endógenos da Tríplice Hélice, necessários para o desenvolvimento tecnológico. Neste contexto, pesquisas nas cadeias produtivas admitem valores às estruturas organizacionais e as transferências de tecnologias, estabelecendo estratégias e redes de cooperação. Portanto, assume-se que a avaliação das relações interinstitucionais para o desenvolvimento sustentável surgem como proposição para trabalhos futuros.

\section{Agradecimentos}

Os autores agradecem ao Programa de Pós-Graduação em Desenvolvimento Rural Sustentável da Universidade Oeste do Paraná (Unioeste) e a Universidade Federal da Grande Dourados (UFGD).

\section{Referências}

Aguiar, L. R. D. (2015). As relações da tríplice hélice nas fundações de apoio brasileiras: uma avaliação da dinâmica de captação de recursos para projetos de inovação (Dissertação de Mestrado, Universidade Federal do Rio Grande do Norte). 
Aigner, F. A. (2011). Contrato de pesquisa, desenvolvimento e inovação entre a universidade e a agroindústria de frangos [Dissertação de Mestrado]. Universidade Federal de Santa Catarina.

Albuqerque, P. P. (2012). Sistema alagoano de inovação: organização institucional necessária para o desenvolvimento (Dissertação de Mestrado, Universidade Federal de Alagoas).

Albuquerque, S. B. (2005). Sistema de inovação baseado em conhecimento e o modelo tríplice hélice: a universidade na construção da vantagem competitiva do setor de tecnologia da informação de Pernambuco (Dissertação de Mestrado, Universidade Federal de Pernambuco).

Almeida, M. C. (2004). A evolução do movimento de Incubadoras no Brasil (Tese de Doutorado, Universidade Federal do Rio de Janeiro).

Almeida, Y. F. (2017). Análise do Sistema Regional de Inovação no Estado do Tocantins (Dissertação de Mestrado, Universidade Federal do Tocantins).

Aloise, P. G. (2017). Ecoinovações no polo industrial de Manaus: direcionadores e fatores determinantes (Tese de Doutorado, Universidade de Caxias do Sul).

Anderle, D. F. (2017). Modelo de conhecimento para representação semântica de smart cities com foco nas pessoas (Tese de Doutorado, Universidade Federal de Santa Catarina).

Andrade, A. M. (2016). O papel das Instituições Científicas e Tecnológicas (ICTS) nos processos de licenciamento e transferência de tecnologia no estado de Sergipe (Dissertação de Mestrado, Universidade Federal de Sergipe).

Araujo, L. V. (2018). Inovação em comunicação no brasil: contexto, desafios e oportunidades (Tese de Doutorado, Universidade Metodista de São Paulo).

Armellini, F. (2013). Patterns of open innovation within product development: a comparative study between Brazilian and Canadian aerospace industries (Tese de Doutorado, Universidade de São Paulo).

Avila, J. C. D. (2016). Fatores que influenciam o desenvolvimento de inovação sob a luz da teoria da Tríplice Hélice (Dissertação de Mestrado, Universidade Federal de Santa Catarina).

Azevedo, J. B. (2014). Desenvolvimento sustentável corporativo: um estudo sobre práticas sustentáveis na indústria gaúcha de máquinas e implementos agrícolas (Dissertação de Mestrado, Universidade Federal de Santa Maria).

Bandeira, R. (2015). Interação universidade-empresa: uma análise da contribuição dos grupos de pesquisa da Universidade Federal de Santa Maria (Dissertação de Mestrado Profissional, Universidade Federal de Santa Maria).

Barreiro, E. R. N. (2015). O parque tecnológico da Paraíba e arranjos institucionais: tessituras do desenvolvimento local - territorial (Dissertação de Mestrado, Universidade Estadual da Paraíba).

Barroncas, K. M. P. A. (2017). Bioeconomia: um estudo das vocações, fragilidades e possibilidades para o desenvolvimento no estado do Amazonas (Tese de Doutorado, Universidade Federal do Amazonas).

Bassani, J. (2018). Avaliação de cenário para o desenvolvimento de uma incubadora tecnológica no município de Araranguá - SC (Dissertação de Mestrado, Universidade Federal de Santa Catarina).

Bencke, F. F. (2016). A experiência gaúcha de parques científicos e tecnológicos à luz da tríplice hélice (Tese de Doutorado, Universidade de Caxias do Sul).

Bittencourt, V. S. (2017). Guia de parceria universidade/empresa: portfólio das patentes depositadas para o NIT/UFTM - 2015 -2017 (Dissertação de Mestrado Profissional, Universidade Federal do Triângulo Mineiro).

Blumm, A. C. N. (2019). Sistematização de procedimento padrão para spin-off acadêmico (Dissertação de Mestrado Profissional, Universidade de Brasília).

Borges, M. A. (2017). Dinâmica das Parcerias Intersetoriais em Iniciativas de Inovação Social: da descrição à proposição de diretrizes (Tese de Doutorado, Universidade Federal de Santa Catarina).

Brandão, J. M. (2012). Sistema Regional de Inovação do Vale do Submédio São Francisco: o caso da Universidade Federal do Vale do São Francisco - UNIVASF (Dissertação de Mestrado Profissional, Instituto Nacional da Propriedade Industrial do Rio de Janeiro).

Brasileiro, H. D. (2018). Universidade Estadual de Feira de Santana (UEFS) e o desenvolvimento da ciência, tecnologia e inovação (CT\&I): um estudo de caso a partir dos aportes da fundação de amparo à pesquisa do estado da Bahia (FAPESB) (Dissertação de Mestrado Profissional, Universidade Federal do Recôncavo da Bahia).

Bravin, S. M. R. (2015). A contribuição do programa mulheres mil para a formação de capital social (Dissertação de Mestrado, Universidade do Contestado, Canoinhas).

Brito, H. N. S. (2018). Análises sobre uma incubadora de empresas na universidade pública: um estudo na INEAGRO/UFPI (Dissertação de Mestrado Profissional, Universidade Federal do Piauí).

Brustolin, V. M. (2014). Inovação e desenvolvimento via defesa nacional nos EUA e no Brasil (Tese de Doutorado, Universidade Federal do Rio de Janeiro).

Bulegon, F. (2019). A contribuição dos distritos industriais para o desenvolvimento local: análise do caso de Chapecó-SC (Dissertação de Mestrado, Universidade Comunitária da Região de Chapecó).

Calderan, L. L. (2012). Análise da interação UNB-Petrobras: O caso do Instituto de Geociências da Universidade de Brasília (Dissertação de Mestrado Profissional, Universidade de Brasília).

Camboim, V. S. C. (2013). Avaliação da interação universidade-empresas-governo no desenvolvimento de projetos inovadores no RN por micro e pequenas empresas (Dissertação de Mestrado, Universidade Federal do Rio Grande do Norte). 
Cardoso, Eduardo Luiz (2013). O sistema de inovação da indústria criativa no estado do Rio Grande do Sul: uma análise da produção do setor audiovisual (Dissertação de Mestrado, Universidade de Caxias do Sul).

Carvalho, N. (2011). Gestão da cooperação: Fatores facilitadores do sistema integrado de acompanhamento de resultados de projetos (Dissertação de Mestrado Universidade Federal de Lavras).

Castelo, A. F. M. (2016). A interação entre universidade-empresa-governo no setor de energia solar fotovoltaica no Ceará: Análise e proposições (Dissertação de Mestrado, Universidade de Fortaleza).

Castillo, L. A. M. (2016). Diretrizes para o desenvolvimento da gestão do conhecimento em parques tecnológicos: estudo de múltiplos casos (Tese de Doutorado, Universidade de São Paulo).

Chais, C. (2014). Transferência de Tecnologia entre Universidades e Empresas: Os Casos UNICAMP-SP e UNISINOS-RS (Dissertação de Mestrado, Universidade de Caxias do Sul).

Chais, C. (2019). Universidades empreendedoras e ambientes de inovação: uma proposta de sustentabilidade econômica para o ensino superior (Tese de Doutorado, Universidade de Caxias do Sul).

Christo, R. S. C. (2011). Comportamento inovador: fatores geradores antecedentes e consequentes (Dissertação de Mestrado Profissional, Universidade Potiguar, Natal).

Cornélio, S. C. (2011). Sustentabilidade no setor de construção civil da região oeste do Paraná (Dissertação de Mestrado, Universidade Federal do Paraná).

Correia, P. C. (2014). Ambientes locais inovadores no contexto do desenvolvimento regional (Tese de Doutorado, Universidade Federal do Rio Grande do Sul).

Costa, C. H. G. (2017). Modelo de gestão estratégica aplicado à agência de inovação do café (INOVACAFÉ) (Tese de Doutorado, Universidade Federal de Lavras).

Costa, D. B. (2013). Obstáculos e soluções no processo empreendedor de criação de spin-offs dentro de incubadoras: um estudo de caso no Ceará (Dissertação de Mestrado, Universidade de Fortaleza).

Costa, E. J. M. (2020). Teoria das Instituições e da Mudança Institucional de Douglass North: Cultura, Estado e Dependência de Trajetória. Cadernos CEPEC, (S.1.), v. 8, n. 2 .

Coutinho, G. A. S. (2017). Gestão de propriedade intelectual nas instituições federais de ensino superior do estado de Goiás (Dissertação de Mestrado Profissional, Universidade Federal de Goiás).

Cunha, D. F. S. (2015). O sentido do Direito e o sentimento do justo (Tese de Doutorado, Pontifícia Universidade Católica de São Paulo).

Dalmarco, G. (2012). Fluxo de Conhecimento na Interação Universidade-Empresa: uma nova visão em setores tradicionais e de alta tecnologia no Brasil e na Holanda (Tese de Doutorado, Universidade Federal do Rio Grande do Sul).

Dantas, L. A. N. A. (2015). Convergência ou não Convergência: A Política de P\&D do Setor Elétrico e a Parceria Universidade Empresa (Dissertação de Mestrado, Universidade de Brasília).

Deboni, M. A. (2010). O gerenciamento da qualidade e sua relação com o sucesso no gerenciamento de projetos (Dissertação de Mestrado, Universidade Estadual do Norte Fluminense Darcy Ribeiro).

Doin, T. A. F. (2016). Governança colaborativa na relação universidade-empresa-governo: para além dos pressupostos da hélice tríplice (Dissertação de Mestrado, Universidade Federal do Espírito Santo).

Eberhart, M. E. (2013). A influência do processo decisório na cooperação governo-universidade-empresa: um estudo de caso sobre a organização universitária (Dissertação de Mestrado, Universidade Positivo, Curitiba).

Edquist, C., \& Johnson, B. (1997). Institutions and organizations in systems of innovation. In: Edquist, Charles, (Ed.). Systems of innovation: technologies, institutions and organizations. London: Pinter, 1997, p. 41-63.

Etzkowitz, H., \& Zhou, C. (2017). Hélice Tríplice: inovação e empreendedorismo universidade-indústria-governo. Estudos Avançados, São Paulo, v. 31, n. 90, pág. 23-48.

Feio, M. A. C. B. N. (2011). Inovação em empresas de serviços: Um estudo de caso do setor de saúde suplementar (Dissertação de Mestrado, Universidade Nove de Julho).

Ferreira, D. L. (2012). O Sistema de inovação do estado da Bahia: uma análise baseada em indicadores de tecnologia e inovação (Dissertação de Mestrado Profissional, Faculdade de Tecnologia SENAI CIMATEC, Salvador).

Ferreira, M. J. (2015). A história da ciência como subsídio para a construção do conhecimento do conceito da dupla hélice (Dissertação de Mestrado Profissional. Universidade, Tecnológica Federal do Paraná).

Ferreira, D. A. (2018a). Interdisciplinaridade e políticas públicas: experiência do Programa Goiás Solar (Tese de Doutorado, Pontifícia Universidade Católica de São Paulo).

Ferreira, R. C. (2018b). Um possível caminho para o desenvolvimento regional endógeno (Dissertação de Mestrado, Universidade Federal da Integração LatinoAmericana). 
Figueiredo, M. G. (2010). Aprendizado para Inovação Tecnológica na Universidade Federal da Paraíba: um estudo à Luz da Tripla Hélice (Tese de Doutorado, Universidade Federal da Paraíba).

Filho, R. B. S. (2009). As relações da tríplice hélice no setor da carcinicultura do Rio Grande do Norte: uma análise a partir das abordagens da imersão social e da dependência de recursos (Dissertação de Mestrado, Universidade Federal do Rio Grande do Norte).

Fiorin, F. S. (2016). Análise dos fatores que conduziram empresa do rio grande do sul a investir na criação de um novo negócio de base tecnológica - SPIN-OFF corporativa (Dissertação de Mestrado Profissional, Universidade do Vale do Rio dos Sinos).

Fontanela, C. (2016). Modelo jurídico para o parque científico e tecnológico Chapecó@: uma proposta a partir da abordagem da tríplice hélice (Tese de Doutorado, Universidade Federal de Santa Catarina).

Forster, J. L. (2016). Orquestração de ecossistemas de inovação: estudo de caso sobre o paralelo vivo Hub de inovações sustentáveis (Dissertação de Mestrado Profissional, Universidade do Vale do Rio dos Sinos).

Furlanetto, B. (2018). O Parque Científico e Tecnológico Chapecó@ e a Unochapecó: tecnologia social e desenvolvimento regional (Dissertação de Mestrado, Universidade Comunitária da Região de Chapecó).

Gomes, N. B. (2014). Sistema regional de inovação da ovinocultura do Mato Grosso do Sul associado ao desenvolvimento da ovelha da raça pantaneira (Tese de Doutorado, Universidade Nove de Julho).

Guedes, C. F. B. (2010). Políticas Públicas de Estímulo à P\&D: uma Avaliação dos Resultados do Programa Regulado pela Agência Nacional de Energia Elétrica - ANEEL (Dissertação de Mestrado, Universidade de Brasília).

Hoffmann, C. (2015). Ciência e tecnologia e a relação com o setor produtivo no Paraná: uma análise a partir de sistemas de inovação (Dissertação de Mestrado, Universidade Estadual de Maringá).

IBGE (2020). Diretoria de Pesquisas, Coordenação de População e Indicadores Sociais, Estimativas da população residente. Data de referência 1 de julho de 2020.

Jaroszewski, C. R. (2018). Os governos estaduais e a política pública de inovação tecnológica: analise a partir do modelo teórico Hélice Tríplice (Tese de Doutorado, Fundação Getúlio Vargas).

Jesus, V. (2018). Tecnologias sociais da região nordeste certificadas pela fundação Banco do Brasil (Dissertação de Mestrado, Universidade Federal de Sergipe).

João, I. S. (2014). Modelo de gestão da inovação social para empresas sociais (Tese de Doutorado, Universidade de São Paulo).

Junior, G. M. C. (2008). O papel da universidade no desenvolvimento local - estudo de caso da UNIFEI, Itajubá, MG (Dissertação de Mestrado Profissional, Centro Universitário Augusto Motta, Rio de Janeiro).

Junior, J. A. B. (2014). Parques tecnológicos como instrumento de apoio ao desenvolvimento industrial de Pernambuco: um sistema em construção (Dissertação de Mestrado Profissional, Universidade Federal de Pernambuco).

Kasczuk, N. O. (2017). Operacionalização do tecnicentro: um estudo comparativo com outros parques nacionais (Dissertação de Mestrado Profissional, Universidade Estadual do Centro-Oeste, Guarapuava).

Kohl, A. (2012). Estratégias e ações das empresas hospedadas no Tecnopuc: implicações da inovação no Desenvolvimento Regional (Dissertação de Mestrado, Universidade de Santa Cruz do Sul).

Koste, R. C. J. (2010). A interação universidade-empresa e a prática da inovação: Potencialização de recursos e construção de espaços de cooperação (Dissertação de Mestrado, Universidade do Vale do Rio dos Sinos).

Kronbauer, E. R. (2015). Fluxo de Conhecimento entre Universidade e Empresa Uma análise de empresas instaladas no TECNOPUC (Dissertação de Mestrado, Pontifícia Universidade Católica do Rio Grande do Sul).

Kuhn, L. D. (2015). Abordagem estratégica de um modelo integrado de gestão de Supply Chain e contribuições do modelo SCOR (Dissertação de Mestrado Profissional, Universidade do Vale do Rio dos Sinos).

Lacerda, A. R. S. (2015a). Parque tecnológico de fármacos e biociências de Pernambuco: uma análise da importância da UFPE na Indução e na Implantação (Dissertação de Mestrado Profissional, Universidade Federal de Pernambuco).

Lacerda, E. C. A. (2015b). A sustentabilidade e suas dimensões como critério de condicionamento e equilíbrio da propriedade privada (Dissertação de Mestrado, Universidade do Vale do Itajaí).

Lain, G. C. (2013). Os Atores de Inovação no Québec: um Estudo Exploratório (Dissertação de Mestrado, Universidade de Caxias do Sul).

Lemos, P. A. B. (2011). As universidades de pesquisa e a gestão estratégica do empreendedorismo - uma proposta de metodologia de análise de ecossistemas (Tese de Doutorado, Universidade Estadual de Campinas).

Lima, M. I. (2019). Liberdade de pesquisa científica e inovação na sociedade do conhecimento: um estudo da possível aplicação da teoria do academic capitalism no Brasil (Dissertação de Mestrado, Pontifícia Universidade Católica do Rio Grande do Sul).

Lira, M. G. C. (2017). O papel dos institutos federais no sistema nacional de inovação: análise da contribuição de um modelo de gestão (Dissertação de Mestrado Profissional, Universidade Federal da Bahia).

Lopes, R. S. P. (2016). Fatores determinantes no processo de desenvolvimento endógeno de um Território: Um olhar para o Município de Ijuí a partir dos atores da tríplice hélice (Dissertação de Mestrado, Universidade Regional do Noroeste do estado do Rio Grande do Sul). 
Lyrio, E. F. (2014). Uma análise da utilização da lei do bem nas micro e pequenas empresas (MPE) de base tecnológica incubadas no vale da eletrônica, em Santa Rita Do Sapucaí (MG) (Dissertação de Mestrado, Universidade do Estado do Rio de Janeiro).

Macedo, C. W. (2017). Interação universidade-empresa-governo: uma análise do arranjo institucional do Porto Digital (Dissertação de Mestrado, Universidade Federal de Pernambuco).

Machado, I. L. (2016). Redes interorganizacionais na conformação de políticas públicas: O caso "Minas Biotec” (Dissertação de Mestrado, Fundação João Pinheiro).

Mafioletti, K. (2016). Empreendedorismo e inovação social na perspectiva da tríplice hélice (Dissertação de Mestrado, Universidade Regional de Blumenau).

Maleane, S. O. T. (2012). Tecnologias de informação e comunicação como meio de inclusão e exclusão social em Moçambique: o caso do ensino superior (Tese de Doutorado, Universidade de Brasília).

Marchi, F. L. (2014). Interação entre os atores: o caso Serra Gaúcha a partir do modelo da Tríplice Hélice (Dissertação de Mestrado, Universidade de Caxias do Sul).

Marinho, T. L. (2014). Identificação dos níveis de interação e cooperação das instituições promotoras de inovação em alagoas: uma proposta para o mapeamento de sistemas regionais de inovação (Dissertação de Mestrado, Universidade Federal de Alagoas).

Mello, P. A. S. (2015). A arquitetura jurídico-institucional de um ambiente de inovação brasileiro: O Parque Tecnológico de São José dos Campos (Dissertação de Mestrado, Escola de Direito de São Paulo).

Mello, R. M. (2017). Modelo de gestão para um Parque Científico e Tecnológico na região das Missões (Dissertação de Mestrado Profissional, Universidade Regional Integrada do Alto Uruguai e das Missões).

Mesel, S. R. F (2013). Um estudo empírico sobre a relação dos agentes da hélice tríplice no contexto da lei de informática (Dissertação de Mestrado Profissional, Universidade Federal de Pernambuco).

Mesquita, A. A. (2016). O uso de indicadores de sustentabilidade no gerenciamento de projetos de tecnologia da informação (Dissertação de Mestrado, Fundação Getúlio Vargas).

Mineiro, A. A. C. (2019). Hélice quádrupla e quíntupla e seus relacionamentos em parques científico-tecnológicos consolidados no Brasil (Tese de Doutorado, Universidade Federal De Lavras).

Mineiro, A. A. C., Souza, D. L., Vieira, K. C., Castro, C. C., \& Brito, M. J. (2018). Da hélice tríplice a quíntupla: uma revisão sistemática. Economia \& Gestão (E\&G), Belo Horizonte, v. 18, n. 51

Mineiro, A. A. C., \& Castro, C. C. (2020). A Hélice Quádrupla e sua relação com a visão de futuro dos Parques Científicos e Tecnológicos consolidados no Brasil. Revista de Administração, Sociedade e Inovação (RASI), Volta Redonda/RJ, v. 6, n. 2.

Moreira, J. S. (2019). A universidade empreendedora na promoção de um ecossistema de empreendedorismo incipiente no IFRJ - Campus Engenheiro Paulo de Frontin sob a perspectiva da "hélice tríplice" (Dissertação de Mestrado Profissional, Universidade Federal Rural do Rio de Janeiro).

Morgades, R. F. K. M. (2016). A universidade empreendedora no novo modo de produção da ciência contemporânea: Um Estudo de Caso da Universidade Estadual Norte Fluminense Darcy Ribeiro - UENF (Dissertação de Mestrado, Universidade Estadual do Norte Fluminense Darcy Ribeiro).

Morone, L. A. F. C. (2003). O banco, o consumidor e o mercado (Dissertação de Mestrado, Pontifícia Universidade Católica de São Paulo).

Nascimento, W. C. (2010). As relações de poder no contexto político-econômico de Foz do iguaçu/PR (Dissertação de Mestrado, Universidade Estadual de Maringá).

Negalho, R. B. (2011). A tríplice: o Estado, as políticas públicas e a política nacional da educação ambiental (Dissertação de Mestrado, Universidade Federal do Rio Grande).

Neto, J. V. G. (2015). Institutions, industrialization and innovation: the three is of Argentina, Brazil and Mexico from 1950 to 2010 (Dissertação de Mestrado, Universidade Federal de Alfenas)

Neto, S. M. (2016). Criação de valor compartilhado e hélice tríplice para a interação universidade-empresa-governo: a construção de um referencial analítico de gestão estratégica (Tese de Doutorado, Universidade Federal de Santa Catarina).

Neves, H. P. (2015). Editais de Inovação da Fundação de Amparo à Pesquisa do Estado de Minas Gerais - FAPEMIG - sob a Ótica da Hélice Tríplice (Dissertação de Mestrado, Universidade FUMEC).

Neves, P. (2006). Aprendizagem tecnológica em empresas no arranjo produtivo de louças em Campo - Largo - PR: o papel da interação universidade, empresa e governo (Dissertação de Mestrado, Universidade Positivo, Curitiba).

Niwa, T. H. (2014). O Modelo da Hélice Triplice Em Consonância Com os Arranjos Produtivos Locais Nas Incubadoras Tecnológicas: Um Estudo De Caso Nas IUTs Da UTFPR (Dissertação de Mestrado Profissional, Universidade Tecnológica Federal do Paraná).

Nogueira, C. A. F. (2014). Análise de viabilidade para implantação de um parque tecnológico no sudoeste goiano (Dissertação de Mestrado, Universidade de Taubaté).

Nunes, B. M. (2013). A influência do modelo de tríplice hélice no grau de maturidade de inovação: um estudo de caso das empresas participantes do projeto PRÓ-INOVA/NAGI no estado do Rio Grande do Norte (Dissertação de Mestrado, Universidade Federal do Rio Grande do Norte). 
Oliveira, G. S. (2019). O papel dos institutos federais com a pesquisa aplicada e a importância do marco legal da inovação: proposta de comunicação para incentivo ao empreendedorismo acadêmico no IFRJ - Pinheira (Dissertação de Mestrado Profissional, Universidade Federal Rural do Rio de Janeiro).

Paim, T. G. S. (2018). A construção de redes de inovação: o parque científico e tecnológico da UFRGS e sua implicação social nas empresas (Dissertação de Mestrado, Universidade Federal do Rio Grande do Sul).

Passoni, W. C. (2011). Adoção de inovação tecnológica: uma análise da interação entre atores (Dissertação de Mestrado Profissional, Faculdade de Estudos Administrativos de Minas Gerais).

Pavinato, C. W. T (2018). Universidade empreendedora na percepção de seus stakeholders: um estudo na Universidade de Caxias do Sul (Dissertação de Mestrado, Universidade de Caxias do Sul)

Pereira, D. V. F. (2013). Análise da valoração de tecnologias nas Universidades Federais do Centro-Oeste (Dissertação de Mestrado, Universidade Federal de Mato Grosso do Sul).

Pereira, R. P. A. (2017). Ações estratégicas de um NIT: um estudo de caso na Universidade Federal do Amazonas (Dissertação de Mestrado Profissional, Universidade Federal do Amazonas).

Piccini, R. A. B. (2018). Sistema regional de inovação do setor de tecnologia da informação da região oeste de Santa Catarina: um estudo exploratório (Dissertação de Mestrado Profissional, Universidade do Oeste de Santa Catarina).

Pinsky, V. C., Moretti, S. L. A., Kruglianskas, I. \& Plonski, G. A. (2015). Inovação Sustentável: Uma perspectiva comparada da literatura internacional e nacional. INMR - Innovation \& Management Review, (S. 1.), v. 12, n. 3, p. 226-250.

Pires, A. M. B. (2008). O poder da relação Universidade-Empresa-Governo para a alavancagem do processo de inovação: uma análise da metodologia prática Centros/Redes de Excelência Petrobras/Coppe com base no estudo do caso CEGEQ-COPPE (Dissertação de Mestrado, Universidade Federal da Bahia).

Pontes, R. J. A. (2008). Avaliação dos fundos setoriais sob a ótica da Hélice Tripla. (Dissertação de Mestrado Profissional, Universidade Federal do Ceará).

Pradella, S. (2015). A construção social da inovação: uma análise a partir das relações entre Universidade, Indústrias e Governo na Microrregião de Santa Cruz do Sul (RS) (Tese de Doutorado, Universidade de Santa Cruz do Sul).

Prates, C. C. (2013). Responsabilidade social corporativa: a evolução e o estágio atual do tema nas subsidiárias brasileira e chinesa do Grupo X (Dissertação de Mestrado, Universidade Federal do Rio Grande Do Sul).

Quadros, P. R. N. S. (2011). As incubadoras de empresas: gênese, desenvolvimento, declínio e perspectivas futuras no contexto político-institucional de inovação tecnológica no Estado da Bahia (1993-2010) (Dissertação de Mestrado, Universidade Federal da Bahia).

Renz, G. S. (2016). Processo de desenvolvimento do noroeste do rio grande do sul sob a ótica dos seus atores - o caso do município de Santa Rosa (Dissertação de Mestrado, Universidade Regional do Noroeste do estado do Rio Grande do Sul).

Resende, R. M. V. (2016). Metodologia para a Implantação de Parquelabs - O caso do Parque Tecnológico de Uberaba (Dissertação de Mestrado Profissional, Universidade Federal do Triângulo Mineiro).

Rezende, J. F. D. (2001). Sistema Local de Inovação: Um Estudo de Caso do CTGÁS (Dissertação de Mestrado, Universidade Federal do Rio Grande do Norte).

Rezende, J. F. D. (2012). Sustentabilidade das empresas associadas à REDEPETRO-RN (Tese de Doutorado, Universidade Federal do Rio Grande do Norte).

Ribeiro, A. C. S. (2006). Modelo de gestão para incubadoras de empresas sob a perspectiva de metodologias de gestão apoiadas em rede sob a configuração da hélice tríplice: o caso da incubadora de empresas (Dissertação de Mestrado Profissional, Universidade Federal Fluminense).

Ribeiro, G. M. C. (2016). O processo de incubação social da Universidade Federal de Goiás: Os desafios para a interação significativa na construção do conhecimento (Dissertação de Mestrado, Universidade Federal de Goiás).

Ribeiro, S. X. (2017a). Contribuições ao estudo da gestão do conhecimento e da colaboração universidade-empresa-governo: proposição conceitual e estudo de casos em Institutos Nacionais de Ciência e Tecnologia no Brasil (Tese de Doutorado, Universidade de São Paulo).

Ribeiro, J. A. (2017b). Desenvolvimento e validação de um modelo de referência para a gestão estratégica do desempenho de parques tecnológicos (Tese de Doutorado, Universidade Federal de Minas Gerais).

Riedo, I. G. (2017). Desenvolvimento da piscicultura em pequenas propriedades rurais: análise no contexto da tríplice hélice (Dissertação de Mestrado, Universidade Federal da Grande Dourados).

Rocha, F. C. A. (2002). O desenvolvimento econômico regional baseado no conhecimento: o caso da Petrópolis-Teresópolis (Dissertação de Mestrado, Universidade Federal do Rio De Janeiro).

Rocha, M. M. (2011). Avaliação da parceria entre indústria farmacêutica e universidade como estratégia para a inovação de medicamentos no Brasil (Dissertação de Mestrado, Universidade Federal Fluminense)

Rocha, R. O. (2014a). Tripla hélice “desmembrada”: A dificuldade da inovação no Brasil (Dissertação de Mestrado, Universidade Federal de Sergipe).

Rocha, R. L. (2014b). Interação universidade-centros de pesquisa e empresas: um estudo sobre o setor de biomateriais do estado do Paraná (Tese de Doutorado, Universidade de São Paulo).

Rodrigues, E. D. (2013). Análise da ambiência institucional de Ciência, Tecnologia e Inovação (CT\&I) na Amazônia Legal (Dissertação de Mestrado, Universidade Federal do Tocantins). 
Rodrigues, F. C. R. (2015). Capacidade institucional de apoio à inovação dos institutos federais e das Universidades Federais no Estado de Minas Gerais: um estudo comparativo (Dissertação de Mestrado, Universidade Federal de Viçosa).

Rodrigues, I. S. (2016). A realidade da universidade empreendedora: uma visão a partir da tripla hélice no caso UFJF (Dissertação de Mestrado Profissional, Universidade Federal Fluminense).

Sacramento, J. M. N. (2011). Ferramentas para adequação das linhas de pesquisas de institutos de pesquisa: o exemplo do Ipen (Tese de Doutorado, Universidade de São Paulo).

Santanna, L. T. (2014). A gestão dos resíduos eletroeletrônicos no brasil e no mundo: legislações, práticas e formas de cooperação interorganizacionais (Dissertação de Mestrado, Universidade Federal de Lavras).

Santos, A. M. (2016). Artefatos para extração e análise de informações em base de dados públicas: uma aplicação para o modelo de hélice quíntupla (Tese de Doutorado, Universidade Nove de Julho).

Santos, L. C. M. (2012). O Mercador de Inovações: A importância da comunicação e das competências nos NITs do Paraná (Dissertação de Mestrado, Universidade Tecnológica Federal do Paraná).

Santos, L. A. S. (2013). Uma análise da relação institucional entre a Universidade Federal de Pernambuco e a refinaria Abreu e Lima (Dissertação de Mestrado Profissional, Universidade Federal de Pernambuco).

Santos, L. C. T. (2017). Influência do modelo hélice tripla na inovação de empresas que participam em redes: o caso da vitivinicultura em Jundiaí (Dissertação de Mestrado, Universidade Paulista).

Santos, R. F. (2015). Design para tecnologia social (DpTS): UM modelo piloto em design sistêmico para transformação social, por inclusão produtiva, de populaçoes de baixa renda (Tese de Doutorado, Pontifícia Universidade Católica Do Rio De Janeiro).

Sartori, V. (2017). InHab-Read - IHR: Metodologia de leitura de entorno para habitats de inovação (Tese de Doutorado, Universidade Federal de Santa Catarina).

Schmitz, A. (2017). A inovação e o empreendedorismo na universidade: um framework conceitual sistêmico para promover desenvolvimento socioeconômico regional e sustentabilidade institucional (Tese de Doutorado, Universidade Federal de Santa Catarina).

Schneider, G. (2017). Modelo de transferência de tecnologia das instituições de ensino superior comunitárias brasileiras (Dissertação de Mestrado, Universidade de Passo Fundo).

Schreiner, T. (2017). Os processos de liderança na implantação de um centro de inovação a partir da perspectiva construcionista (Dissertação de Mestrado, Universidade Federal de Santa Catarina).

Silva, A. G. (2015a). Interações da hélice tríplice na constituição da força motriz da inovação e do empreendedorismo (Dissertação de Mestrado, Universidade de Fortaleza)

Silva, A. F. M. (2017). Capital social e estratégias de inovação na gestão de parques tecnológicos: o caso Sapiens Parque (Dissertação de Mestrado, Universidade Católica do Paraná, Curitiba).

Silva, A. D. F. (2014a). O Processo Regulador na [Re]conversão de um Arranjo Produtivo Local: O caso do Portomídia - Centro de Empreendedorismo e Tecnologia da Economia Criativa (Dissertação de Mestrado, Universidade Federal De Pernambuco).

Silva, A. R. S. (2015c). A cooperação técnica entre as forças armadas e o setor acadêmico: um estudo sobre os escritórios da Marinha do Brasil localizados em universidades federais (Dissertação de Mestrado Profissional, Instituto Nacional Da Propriedade Industrial, Rio de Janeiro).

Silva, C. V. (2010). Processo de transferência de conhecimento na interação universidade-empresa: programas de incubação do Distrito Federal (Dissertação de Mestrado, Universidade de Brasília).

Silva, F. S. T. (2014c). Mecanismos da lei do bem para a inovação tecnológica: um estudo do incentivo à P\&D nas grandes empresas do parque tecnológico do Rio de Janeiro (Dissertação de Mestrado, Universidade do Estado do Rio De Janeiro.)

Silva, F. I. R. (2012). O fomento à inovação e seus impactos nos resultados das Micro Pequenas e Médias Empresas à luz da abordagem da Tríplice Hélice (Dissertação de Mestrado, Universidade Estadual do Ceará).

Silva, G. F. (2018a). Conectando saberes: uma metodologia para criação de propostas de valor (Dissertação de Mestrado Profissional, Universidade Federal do Rio Grande do Norte).

Silva, H. S. S. (2015b). Universidade e empresa: uma análise das relações científicas e tecnológicas entre a Universidade Federal de Roraima e as empresas do estado de Roraima (Dissertação de Mestrado, Universidade Federal de Roraima).

Silva, L. F. B. (2007). Estratégias de determinação dos fatores de decisão dos tomadores de microcrédito (Dissertação de Mestrado Profissional, Universidade Federal do Ceará).

Silva, L. F. M. (2018b). Relações do processo de cooperação universidade-empresa: um estudo de caso no interior do Paraná (Dissertação de Mestrado Profissional, Universidade Estadual do Centro-Oeste, Guarapuava).

Silva, P. H. T. (2016). Financiamento à inovação e interação entre atividades científicas e tecnológicas: uma análise a partir do PAPPE (Dissertação de Mestrado, Universidade Federal de Uberlândia).

Silva, R. C. (2019). Mapeamento do ecossistema Alagoano de startups (Dissertação de Mestrado Profissional, Universidade Federal De Alagoas).

Silva, R. M. (2011). Um Modelo para Análise da Sustentabilidade de Fontes Elétricas (Tese de Doutorado, Universidade Federal de Pernambuco). 
Research, Society and Development, v. 10, n. 9, e14410918036, 2021

(CC BY 4.0) | ISSN 2525-3409 | DOI: http://dx.doi.org/10.33448/rsd-v10i9.18036

Silva, S. M. (2018c). As políticas de ciência e tecnologia a partir da criação do Ministério de Ciência e Tecnologia. Um novo padrão de pesquisa e as implicações para as universidades públicas (Tese de Doutorado, Universidade Federal do Rio de Janeiro).

Silva, Y. F. O. (2014b). Universidade e desenvolvimento local: o caso da Universidade Estadual de Goiás (Tese de Doutorado, Universidade Federal do Rio de Janeiro).

Siqueira, E. M. (2007). A participação dos entes universidade, indústria e governo em incubadoras de base tecnológica (Dissertação de Mestrado, Universidade Federal de Santa Catarina).

Soares, J. A. (2009). O Papel do Governo, Universidade e Empresas na consolidação da cadeia produtiva do Biodiesel no Brasil: estudo de caso exploratório baseado na abordagem da Hélice Tripla (Dissertação de Mestrado, Centro Universitário da FEI, São Bernardo do Campo).

Sobrinho, I. C. (2017). Determinantes dos depósitos de patentes em ciências da vida e da saúde nas Universidades Federais Mineiras: Uma análise de dados em painel para o período 1995-2016 (Dissertação de Mestrado, Universidade Federal de Juiz de Fora).

Sonego, V. M. (2015). Fluxo de conhecimento na interação universidade-empresa: o desenvolvimento da soja no interior do Paraná (Dissertação de Mestrado, Pontifícia Universidade Católica Do Rio Grande do Sul).

Sousa, D. C. (2015). A inovação e a gestão das empresas embrionárias de inovação tecnológica: uma análise do processo de pré-incubação (Dissertação de Mestrado, Universidade Paulista).

Sousa, M. A. (2019). Internacionalização De Parques Tecnológicos: Estudo de Caso No Parque Tecnológico Itaipu-Brasil (PTI-BR) (Dissertação de Mestrado Profissional, Universidade Estadual do Oeste do Paraná, Foz do Iguaçu).

Souza, S. V. (2015). O regime jurídico dos agrotóxicos e o sistema da tríplice responsabilidade (Dissertação de Mestrado, Universidade Católica de Santos).

Terra, B. R. C. S. S. R. (1999). Escritórios de transferência de tecnologia em universidades (Tese de Doutorado, Universidade Federal do Rio de Janeiro).

Toledo, F. L. B. (2016). Fatores determinantes na geração de patentes (Dissertação de Mestrado, Universidade Regional de Blumenau).

Torres, F. S. (2011). Modelagem de Equações Estruturais Para Avaliar As Estratégias Corporativas Sustentáveis: Um estudo em empresas que atuam e confecção (Dissertação de Mestrado, Universidade Federal do Ceará).

Toscano, F. L. P. (2014). Transferência de tecnologia entre empresas e universidades: dificuldades enfrentadas no processo Vitória (Dissertação de Mestrado, Instituto Capixaba de Pesq. Em Cont. Econ. e Finanças, Vitória).

Tosta, K. C. B. T. (2012). A Universidade como catalisadora da inovação tecnológica baseada em conhecimento (Tese de Doutorado, Universidade Federal de Santa Catarina).

Valladares, P. S. D. A., Vasconcellos, M. A. \& Di Serio, L. C. (2014). Innovation Capability: A Systematic Review of the Literature. Revista de Administração Contemporânea - RAC, Rio de Janeiro, v. 18, n. 5, art. 3, pp. 598-626.

Webber, L. S. (2018). Criação de um parque tecnológico na cidade de Osório: proposta de um roteiro e sensibilização dos atores da tríplice hélice e da sociedade (Dissertação de Mestrado Profissional, Universidade do Vale do Rio dos Sinos).

Zimba, H. F. (2010). A dimensão política e o processo de institucionalização da ciência e tecnologia em Moçambique (Tese de Doutorado, Universidade de Brasília). 